\title{
A review of dorsal metacarpal disease (bucked shins) in the flat racing horse: prevalence, diagnosis, pathogenesis, and associated factors
}

\begin{abstract}
Dorsal metacarpal disease (DMD) is the most common cause of lostdays to training and racing in Thoroughbred racehorses. Colloquially termed 'bucked' or 'sore' shins, this initially painful condition commonly occurs in the first season of training and can raise welfare concerns. Clinical signs include pain with digital palpation and swelling on the dorsal, and sometimes dorso-medial, aspect of the third metacarpal (McIII). Periostitis and excessive growth of periosteal bone can be present as a response to high strain cyclic fatigue. Whilst DMD can resolve with rest or reduced exercise, it can leave bone susceptible to future catastrophic fracture at the same site, particularly saucer fractures of the lamellar bone of the diaphysis. Some trainers continue to work an animal through DMD, with the view that it will only happen once, but it can reoccur. Additionally, the animal is in discomfort and has a weakened skeletal system. In vivo studies of the effects of cyclic strain on the skeletal system of Thoroughbreds are notoriously difficult, due to the many variables involved and in vitro studies cannot mimic true training and racing conditions. Variables affecting the loading of the McIII such as exercise regimes, location, speed, direction, conformation, surfaces, farriery, and diet have all been investigated to ascertain their influence, if any, on disease predisposition and onset. In the 1990's, it was believed that certain training methods and the young age at which Thoroughbreds commenced training were the main cause of DMD. Since then, the cause of DMD has been linked to excessive bone loading stress, with bone cell absorption exceeding replacement. Other studies have reported that lengthy periods of stabling and lack of access to short bursts of high speed exercise, results in reduced bone mineral content and strength in the equine McIII, thus predisposing it to fatigue.
\end{abstract}

Keywords: racehorse, injury, thoroughbred, bone, training
Volume 5 Issue 6 - 2017

\author{
S Couch,' BD Nielsen² \\ 'Royal (Dick) School of Veterinary Studies, University of \\ Edinburgh, United Kingdom \\ 2Department of Animal Science, Michigan State University, USA
}

Correspondence: Brian D Nielsen, Michigan State University, Department of Animal Science, 474 S. Shaw Lane, East Lansing MI 48824 I225, USA, Tel 517432 I378, Fax 517353 1699, Email bdn@msu.edu

Received: September 13, 2017| Published: September 25, 2017
Abbreviations: McIII, third metacarpal; DMD, dorsal metacarpal disease; CT, computed tomography; MRI, magnetic resonance imaging; pQCT, peripheral quantitative CT; GRF, ground reaction forces; SMA, second moments of area; NA, neutral axis; CSA, cross sectional area; BMD, bone mineral densities; AHW, automated horse walkers; SHA, secondary haversian activity

\section{Introduction}

A Thoroughbred can gallop within hours of birth ${ }^{1,2}$ and, when trained, can sustain speeds of $56-64 \mathrm{~km} / \mathrm{h}$ for up to $1.6 \mathrm{~km} .^{3}$ The evolutionary cost has been a reduction in the size and weight of the limbs, a transition from five digits to one and an increase in muscle mass; the average weight of a racehorse being $450-550 \mathrm{~kg} .{ }^{4-6}$ These adaptations have led to vulnerabilities in the limbs and a reduced ability of the third metacarpal (McIII) to adapt quickly to changes in ground profile. ${ }^{7}$ The McIII or cannon bone forms an integral part of the shock absorbing, weight-bearing system of the lower forelimb. Training and racing induces an increase in diaphyseal thickness of the McIII (according to Wolff's law) to withstand strain and reduce injury. ${ }^{8,9}$ As in all mammalian bone, if repetitive high speed cyclic exercise is introduced before bone has adequately adapted, damage in the form of micro-fracture can occur - as is the case with dorsal metacarpal disease (DMD). In response to this kind of fatigue damage, excessive periostial bone growth (predominantly over the dorsal McIII) occurs. The material properties, geometry and type of bone affect the type and degree of response. Racehorses are more susceptible to fatigue fractures than other mammals, as equine bone produces higher peak strains. ${ }^{10}$

Catastrophic fractures of the scapula, tibia and pelvis in American racehorses were reported to be a corollary of previous stress-related bone injury ${ }^{3,11}$ stated that $12 \%$ of catastrophic fractures of the McIII occurred at the site of previous DMD episodes. An understanding of DMD, including how to prevent it, is important to improve animal welfare and to decrease expenses associated with veterinary care.

\section{Prevalence}

Sometimes seen bilaterally, DMD is rare in hind limbs and has been reported to have a recurrence rate of up to $40 \% 0^{3,12}$ Norwood reported that $70 \%$ of Thoroughbreds in training and under twoyears of age experienced DMD,${ }^{13}$ whilst Buckingham and Jeffcott reported an $80 \%$ incidence amongst young racehorses in Australia. ${ }^{14} \mathrm{~A}$ later study in the same country reported that $42 \%$ of 2 -year-old racehorses were affected..$^{15}$ In contradiction, Clegg stated that DMD prevalence in an Australian cohort study was $2 \%{ }^{16}$ In a survey conducted by the Japanese Racing Association, a 66\% incidence of 'bucked shin complex' was recorded in horses during their first 8months of training, ${ }^{17}$ whilst Katayama et al. reported a $66 \%$ incidence on dirt tracks during the first 32 months of training. ${ }^{18}$ Others have reported a $20-30 \%$ prevalence. ${ }^{19,20}$ The latter authors stated that their results reflected a decrease in the disease in recent times. In a sample size 
of 486 racehorses in Australia, 24\% to 36\% percent of $2 \mathrm{yr}$-old horses presented with 'shin soreness' whilst only $7 \%$ to $12 \%$ of 3 yr-olds were affected. ${ }^{12}$

\section{Clinical signs and diagnostic techniques}

i. May be asymptomatic in the early stages

ii. Lameness of varying degrees may be visible, but is not always present in the early stages.

iii. Stride impairment, particularly at a gallop when gait can be "choppy". ${ }^{21}$

iv. Radiography can reveal thickening of the dorsal $\mathrm{McIII}^{20}$ but cannot differentiate between cortical and trabecular bone reaction. ${ }^{1}$ At least a $30 \%$ increase in bone mineral density is needed before it will show up radiographically. ${ }^{22}$

v. Palpation of the McIII may reveal heat, swelling over the dorsal/ dorsomedial aspect of the McIII and a positive pain response. ${ }^{20,23,24}$

vi. Scintigraphy can show active bone growth over the dorsal cortex. ${ }^{25}$

vii. Computed tomography (CT) and magnetic resonance imaging (MRI) show more detailed change, ${ }^{26}$ but peripheral quantitative $\mathrm{CT}$ (pQCT) is currently the most accurate way of assessing in vivo bone strength and dimensions. ${ }^{27}$

\section{Pathogenesis}

Norwood stated that abnormality and periostitis over the dorsal McIII area associated with DMD were consequences of sub-periosteal haemorrhage, multiple micro-fracture and secondary callous formation..$^{13}$ The haemorrhage was purported to have been caused by a tearing away of periosteum, caused by 'concussive high speed work', a feature of training and racing. Nunamaker contradicted that DMD was a result of the McIII's adaptive response to exercise and the strains exerted on it at different speeds and gaits. ${ }^{3} \mathrm{He}$ further suggested that the bending of the McIII (under stress) induced abnormal bone formation over the dorsal aspect. However, more recently, it has been suggested that a decline in bone mass associated with a lack of high speed exercise that accompanies stalling of horses may be the cause of decreased bone strength, precipitating DMD when high speed exercise is introduced into a training program. ${ }^{28}$

\section{Wolff's law}

In 1892, Julius Wolff (a German anatomist) stated that bone will adapt to loading through modelling and remodelling and this has become known universally as 'Wolff's law'. ${ }^{29}$ Frost $^{30,31}$ revised Wolff's Law stating that:

a. "It is flexing of the bone, not stress that is the principle trigger for remodelling

b. Repetitive and not static loading triggers remodelling

c. In flexed bone the affected surface is drawn towards the concave side"

\section{Modelling and remodelling}

Modelling is a natural process in immature mammals, altering the shape of the skeleton as it grows. It is at its most prolific stage during the growth of long bones such as the McIII and adapts bone to withstand loading. ${ }^{32-34}$ The remodelling process (removal and replacement of bone) replaces primary bone in the juvenile vertebrate and maintains the adult skeleton through osteoclastic and osteoblastic activity. ${ }^{35}$ The natural corollary of aging, weakness and/or damage to the skeleton is a remodelling response as the bone attempts to repair itself. Adaptive change is the gradual and natural response to loading forces over time, but repetitive high speed loading can lead to the rate of bone resorption exceeding bone replacement causing weakness and susceptibility to stress-induced microfracture. This non-adaptive change is a response designed to increase inertial potential. ${ }^{36}$

According to Norwood, the time between osteoclastic and osteoblastic activity is around a month, followed by a week of osteoblastic activity and approximately 3 months until bone reaches previous strengths. ${ }^{13}$ During this time bone is vulnerable and the responses to stress depend on the magnitude and trajectory of the forces applied. Stated that remodelling processes are suppressed when a horse is in training. ${ }^{35}$ However, research by Hoekstra et al. showed that bone mass in the equine McIII adapts to its loading situation and can be lost during stall rest. ${ }^{37}$ Loss of bone mass due to reduction in exercise intensity, combined with the re-absorption of bone minerals in the first 50-60days of training could increase stress injuries on resumption of training, ${ }^{38}$ particularly as schedules are often 'squeezed' to fit racing timetables. The type of bone, as well as its properties and matrix, affect the speed at which micro-fracture, modelling and remodelling occur. For instance, cortical bone models and remodels eight times slower than trabecular bone. ${ }^{39}$ Regardless, though one must be cautious about overloading bone without allowing adequate time to modify via remodelling. Stalling of horses without access to exercise at speed may result in bone loss associated with modelling that accompanies decreased loading.

\section{Loading and strain}

Bone requires a degree of loading to maintain mass and shape in order to withstand the rigours of daily activities. During exercise, the dorsal cortex of the McIII responds to the tensile and compressive loading strains by remodelling. ${ }^{26,40}$ Bending rigidity is assumed to reflect the orientation of bending forces. ${ }^{41}$ Whilst strain increases with speed and fatigue, ${ }^{42,43}$ no studies to date have been able to identify levels of loading-induced strain on the McIII during normal maintenance activities, e.g. standing, walking and sleeping. ${ }^{44}$ Speeds of 10 metres per second $(\mathrm{m} / \mathrm{s})$ can elicit $>2,000$ microstrains ( $\mu$ strains) on the dorsal cortex of the McIII ${ }^{43,45}$ and 3,000 $\mu$ strains (at 16-19m/s) was insufficient to stimulate an adequate remodelling response in a study by Davies. ${ }^{46}$ An in vivo strain gauge study found that McIII's of young Thoroughbreds withstood compressive microstrains ( $\mu$ strains) of up to 5,670 dorsally at galloping speeds. ${ }^{3}$ Slow speeds increase peak strains over the medial cortex. ${ }^{47}$

The cross-sectional shape of the McIII (ellipse) both inhibits and equalises directional load and Les et al. stated that the McIII serves to "augment and regulate" the sagittal bending of bone when a horse is racing. ${ }^{7}$ During locomotion, loading of the equine McIII comes from opposing directions. Body mass exerts compression downwards whilst ground reaction forces (GRF) generate load upwards. The degree of bending or stress to the bone is complex and depends on the magnitude and orientation of the force and also the shape, condition, and constituents of the bone. ${ }^{41}$ Metacarpals bend mainly in the saggital plane during life..$^{23}$ Moreira et al. stated that the lateral and medial cortices of the McIII have almost the same biomechanical properties and elastic modulus and that a correlation exists between bone density and biomechanical properties. ${ }^{48}$ They also noted that 
bone widths in the dorsal, palmar, lateral, and medial aspects of the diaphysis are varied. However, data were floored, as training histories were unknown, making it impossible to assess how far differing bone geometry was due to adaptive change.

Bone area is distributed in such a way that it minimises loading strain. ${ }^{41,49,50}$ The diaphysis is generally the stiffest part of the McIII, resisting bending or failure through energy absorption. ${ }^{7}$ Gibson et al. reported that the dorsal surface is less stiff than the lateral surface. ${ }^{10}$ Loading of the McIII during training is maximal in the mid-diaphyseal region..$^{51}$ Compressive strains peak over the medial cortex during mid-stance and are probably a response to body mass. ${ }^{52}$ Strain is intermittent and variable over the lateral cortex suggesting a possible role in balance and body mass support. ${ }^{52}$ When a Thoroughbred gallops, the neutral axis rotates slightly and peak strains switch from the medial cortex to the dorso-medial cortex. ${ }^{47}$ Davies and McCarthy stated that peak strains on the dorsal cortex of the McIII in Thoroughbred yearlings occurred immediately after hoof impact when decelerating and/or turning. ${ }^{53}$ Strain increases on the trailing forelimb and dorsal aspect of the MCIII when a horse is racing despite weights, surface, or farriery. ${ }^{43}$ Strain levels were found to drop by $42 \%$ during the transition from trot to canter in an experiment by Rubin \& Lanyon ${ }^{42}$ whilst Rubin et al. ${ }^{54}$ argued that peak strains occur at canter. ${ }^{54}$ However, their sample (3 Thoroughbreds) was small and results for cortical strain densities were disparate. The authors proposed that the disparity could be evidence of an "internal homeostatic" response not linked to strain, or that only a brief period of stimuli is needed to maintain bone integrity. Uniformity in reaction to peak strain observed in other mammals was attributed to a "safety margin" between peak strain and failure. ${ }^{42}$

\section{Aetiology}

Breed: Whilst DMD is predominant in Thoroughbreds, while Goodman reported an incidence of 5-50\% in twoyear-old Quarter horses in training. ${ }^{55}$ Nunamaker stated that DMD is occasionally diagnosed in Standardbreds. ${ }^{56}$ Nunamaker et al. ${ }^{24}$ found no difference between the McIII bones of Thoroughbreds and Standardbreds in a reversed cyclic bending study. ${ }^{24}$

Age: DMD is rarely seen in the mature equine skeleton (age 4 and over) in Thoroughbreds. ${ }^{23,57}$ Whilst cases have been reported between the ages of 8 months and 3years ${ }^{58}$ it usually affects two-year-olds in their first year of training. ${ }^{18,20,23,59}$ It should be noted that National Hunt Horses in Northern Ireland have been reported to experience DMD as five-year-olds, particularly when stalled for significant amounts of time after weaning and when not raced until that age.

Young mammals show strong modelling and remodelling responses to mechanical loading, whilst older adults produce a small and/or limited response. ${ }^{41,60,61}$ The skeleton of a young horse is capable of more rapid remodeling than that of mature horses. Whilst it is generally accepted that cross sectional area (CSA) and cortical thickness of the mammalian McIII increases with age, ${ }^{62}$ the McIII's of young horses were more susceptible to fatigue in a study by Nunamaker et al. ${ }^{24}$ Primary bone is stronger than remodelled bone, so the latter can lead to inferior mechanical properties in the skeleton of juvenile horses. ${ }^{63}$ Nunamaker et al. ${ }^{57}$ stated that changes to the midshaft of the McIII occurred mainly between ages 2 and 3 in Thoroughbreds and Standardbreds, occasionally continuing until age $4 .{ }^{57}$ In another study, minimal changes occurred in yearling Thoroughbreds, was less in adults, and greater in Thoroughbreds than in Standardbreds. ${ }^{57}$ This study used second moments of area (SMA) and assumed that cross sectional properties link to cross sectional strength and did not take into account the shift in the neutral axis (NA) brought about by axial compression. Leiberman et al. ${ }^{41}$ later identified this shift in NA in an in-vivo treadmill experiment using rosette strain gauges on sheep metatarsals. ${ }^{41}$ Bone tissue in 1- and 2year-old horses is more porous and less mineralised than older horses. Secondary osteon formation throughout the cortex of older horses reduces the likelihood of microfracture and therefore predisposition to DMD. ${ }^{64}$

Back et al. ${ }^{65,66}$ stated that age has little effect on kinematics. ${ }^{65,66}$ In contrast, Butcher and Ashley-Ross found that 2year-olds had a faster and greater rate of fetlock joint dorsi-flexion and a shorter time from hoof impact to mid-stance. ${ }^{67}$ The longer the impact force lasts, the more opportunity there is for GRF dissipation. Whilst Butcher and AshleyRoss proposed that the results were probably due to immaturity of the suspensory apparatus, ${ }^{67}$ this has significant implications regarding bone fatique of the McIII.

Gender: Lemazurier et al ${ }^{68}$ stated that ossification occurs earlier in fillies and this can affect bone strength and maturity. ${ }^{68}$ In contrast, an ultrasound study of cortical bone showed that geldings in training had larger CSA's and strength in their McIII's than fillies or entire colts, but lower bone mineral densities (BMD). ${ }^{62}$ Whilst osteopenia has been reported in other castrated animals,${ }^{69}$ no research has indicated a predisposition to exercise-related fractures in Thoroughbred geldings. Little difference in loading strains was found on the dorsal cortex of Thoroughbred fillies and geldings that had been exercised identically. ${ }^{70}$

Genetics and Epigenetics: Research from the $21^{\text {st }}$ century highlights the interaction between environment and genotype. ${ }^{29} \mathrm{Up}$ to $50 \%$ of differences in limb bone geometry within certain human populations are attributed to genetics. $7^{1,72}$ Bone morphology is also under genetic control. ${ }^{73}$ Wallace et al. ${ }^{74}$ stated that genetics significantly affected cortical bone geometry in the femoral diaphyses of wheel-exercised mice, where periosteal enlargement and endo-cortical expansion occurred independently of the amount of exercise. ${ }^{74}$ In human bone, genetics have been shown to play a major part in the aetiology of osteoporosis. ${ }^{75,76}$ In a study of McIII bones taken from 6 yearling and 6 mature Thoroughbred racehorses, Davies found a relationship between peak strains and bone geometry. ${ }^{77}$ Furthermore, the longer the McIII bone, the higher the load is at flexion of the dorsal cortex. ${ }^{48}$

Racecourse surfaces: Limb bones remodel when GRF is both high and vertical ${ }^{41}$ and vibration at a level of 30-40 Hertz is sufficient to trigger fatigue injury in bone. ${ }^{78}$ The materials used on racing and training surfaces affect the acceleration rates of hoof impact and GRF, both of which increase with speed. A synthetic track creates lower hoof acceleration and GRF than turf and dirt and also alters the angle at which the hoof enters the surface. ${ }^{79}$ Dirt surfaces are known to be the hardest and the incidence of DMD is reported as being higher in the United States where dirt is most commonly used for racing. ${ }^{80}$ Setterbo et al. ${ }^{81}$ stated that a synthetic race surface (made of sand, rubber, and polypropylene) caused less impact and hoof shock at landing and take-off than turf and dirt, with 26 to $73 \%$ less impact and loading force than dirt. ${ }^{81}$ However, these data came from a simulated 'trackin-a-box' experiment, where laboratory conditions and track testing devices vary. Laboratory tests cannot replicate natural hoof impact velocities accurately and studies using racehorses on the track with accelerometers/force plates are fraught with numerous confounding factors and variables, for example: 
a. Weather, temperature and humidity ${ }^{82}$

b. Human opinion re: the 'going' 79

c. Differing equipment

d. Differing surface constituents

e. Surface maintenance during trial e.g. harrowing

f. Kinematics affected by equipment ${ }^{79}$

g. Horse body mass

h. Small sample ${ }^{79,80}$

\section{i. Age of synthetic surface}

Crevier-Denoix et al. ${ }^{79}$ noted that hoof angle in relation to the track on landing was larger when cantering on turf than on synthetic. ${ }^{79}$ Hoof angles vary between forelimbs and hind-limbs, but with only a limited number of studies of fore-limb kinematics on racing surfaces, ${ }^{21,79}$ there are insufficient data to compare hoof angle with the incidence of strain pathology on the McIII. The onset of DMD occurred after 51 fast kilometres on dirt and 138 fast kilometres on wood fibre in a study of 171 similarly-trained Thoroughbreds racehorses in a study by Moyer et al. ${ }^{83}$ However, variables regarding training regimes were not included. In contrast, a study by Davies found that track surface had no effect on the incidence of DMD in 16 to 19 month-old Thoroughbreds in training. ${ }^{43}$

Speed: One difficulty when reviewing global literature on racing speeds is the variance in terminology and speed descriptions. A 'gallop' in the United States = a European 'canter' and is usually somewhere between 24 and $48 \mathrm{~km} / \mathrm{hr}$. In Australia, a 'gallop' is sometimes described as anything over $48 \mathrm{~km} / \mathrm{hr}$. In a United States study, Rubin et al. ${ }^{54}$ stated that a slow trot was 2.3 to 3.3 metres per second $(\mathrm{m} / \mathrm{s})$, a fast trot 3.5 to $6.0 \mathrm{~m} / \mathrm{s}$, and a canter 6.0 to $8.8 \mathrm{~m} / \mathrm{s} .{ }^{54}$ In a New Zealand study, a canter was described as $13.3 \mathrm{~m} / \mathrm{s} .{ }^{84}$ A gallop in the United States has been described as around $11 \mathrm{~m} / \mathrm{s}$ and breezing as 15 to $16 \mathrm{~m} / \mathrm{s} .{ }^{85}$ The leading forelimb experiences highest loading on entering the suspension stage of a gallop ${ }^{86}$ and thickening of the dorso-medial cortex occurs as a response to high-speed exercise. ${ }^{46}$ Several studies have shown that training increases the CSA (and therefore bone strength) of the McIII. ${ }^{87,88}$ A huge decrease (98\%) in risk of DMD occurred with every extra mile worked at high speed and increases in distances cantered raised risks by $33 \% .{ }^{85} \mathrm{~A}$ study by Verheyen et al. ${ }^{20}$ contradicts Boston and Nunamaker's ${ }^{85}$ findings by showing that hazard ratios increased with short periods ( $<1$ month) of high speed work ( $\geq 15$ seconds/furlong).

Direction: Thoroughbreds will swap leading legs several times during a race with the inside forelimb normally leading around turns, with a switch to the outer fore when running on the straight. Lead changes are common in the final furlong, possibly to enable the horse to take an extra breath, or perhaps due to muscle fatigue in the leading limb. Track direction varies both globally and regionally. For instance, United States tracks always run counter-clockwise and, in Australia, track directions vary from state to state. Studies examining the effects of track direction on forelimbs have had varied results. In one Australian study it was stated that the reason for larger cortical CSA and McIII diameters in the right forelegs of an entire sample was partly due to the use of counter-clockwise tracks. ${ }^{62}$ In contrast, another Australian study stated that dorsal cortical size increased more in the left leg than the right. ${ }^{46}$ However, as radiographic views were taken from only one side of each McIII and failed to account for geometric unsharpness (penumbra), the results of this study should be questioned. In bilateral cases of DMD in the United States, the left McIII was affected before the right and Nunamaker attributed this to counter-clockwise racing. ${ }^{3}$ In other United States, United Kingdom, and Australian studies, Thoroughbred forelimb injuries to racehorses were equally distributed ${ }^{89-91}$ whilst Clanton et al. ${ }^{92}$ noted that catastrophic fractures commonly occur on the last turn of a race..$^{92}$

Camber: Tracks in the United States are flat, whilst in Europe, where turf is the prevalent surface, racecourse design and direction vary. Slopes, cambers, uphill sections, twists and turns are often included in the layout and are more weather-dependant. Races may be run clockwise, counter-clockwise, or straight. Characteristics of a track can alter gait ${ }^{93}$ and increase strain, but how far this and other track variables affect skeletal adaptation of the McIII or the incidence of saucer fractures as a corollary of DMD is unknown. Davies concluded that camber does not affect the prevalence of DMD ${ }^{43}$ In a study using externally fixed markers by Hobbs et al. ${ }^{94}$ six horses (of unstated breed) were walked, trotted, and cantered on flat and banked curves in a 10-m lunging circle. ${ }^{94}$ The McIII and MtIII angles of inclination were significantly greater on the flat curve than the banked and increased in line with speed. The accuracy of external markers is questionable, due to the fact that tissues and underlying anatomy can move and tape and gadgetry may affect limb proprio-reception and therefore gait. ${ }^{95}$

Breeding and foal management: Exercise is essential for maintaining bone strength and increasing bone mass. ${ }^{96}$ Allowing foals to exercise freely with their dams should be adequate to ensure normal bone development. The amount of exercise a Thoroughbred foal receives during early life can depend on many factors including stabling, illness, and herd dynamics. Forced exercise of foals is rare on Thoroughbred breeding establishments. Studies into the effects of forced exercise in foals prior to commencement of training have reported no incidents of musculo-skeletal damage and show a positive effect on cartilage. ${ }^{97,98}$ In animals, BMD plays a role in bone strength. ${ }^{99}$ Immobility in both humans and horses can cause osteoporosity. In a study by Cornelissen et al. ${ }^{100} \mathrm{BMD}$ and CSA in the McIII's of Dutch Warmblood foals (0 to 5months) were lower when boxed for long periods, compared to those kept on pasture, or in training. ${ }^{100}$ When the same three groups of foals were exercised for a further 6months, differences in CSA disappeared and BMD decreased, particularly in the dorsal cortex. A higher bone density in this area is known from previous studies. ${ }^{64}$ In an 8 week study of 20 week-old foals, ${ }^{28}$ radiographic bone aluminium equivalence (an indicator of bone mineral content) showed increased cortical size and BMD in exercised foals (82-m daily sprints for 5 $\mathrm{d} /$ week) in comparison with a boxed control group and a group contained within a 992-square metre yard. Studies of this kind are problematic due to difficulties assessing all physical movements of free or confined horses.

Foal and yearling sales preparation: In Northern Europe, Thoroughbred foal and yearling sales occur around the beginning of November. To enhance the overall appearance of the animal, the development of a winter coat is kept at bay. As rugging of foals is problematic, they are usually boxed at night and during cold spells, reducing their access to exercise. Some foals are boxed for long periods to avoid getting cuts and bruises which are considered by some to detract from saleability. For conditioning, at least 6weeks preparation is required whilst 3 to 4 months pre-sale confinement is not unusual. ${ }^{96,101}$ During this time, foals are usually walked in-hand, 
lunged for short periods, and potentially turned out for a few hours and brought in at night. In an experiment by Buckingham and Jeffcott, Standardbred yearlings experiencing long periods of sub-maximal exercise lost BMD $(n=5) .{ }^{101}$ During yearling sales preparation, colts tend to get more exercise than fillies ${ }^{84}$-possibly due to colts being generally harder to train and condition. Colts are generally more valuable which may suggest that more time is spent on conditioning colts through exercise to enhance their saleability.

Pre-training: Bolwell et al. ${ }^{101}$ reported that in a study of $114 \mathrm{New}$ Zealand Thoroughbreds, 24 horses spent only 11-15days in pretraining. ${ }^{102} \mathrm{~A}$ horse in the earlydays of pre-training normally does no fast work and spends long periods in a box stall where strain is reduced due to lack of free exercise. ${ }^{103}$ This could follow previous immobility due to sales preparation. Higher strains on the dorsal McIII have been observed in yearlings ${ }^{53}$ and re-absorption of bone minerals has been reported in the first 50 to 60 days of training. ${ }^{38} \mathrm{Nielsen}$ et al. ${ }^{103}$ reported a marked decrease in BMD in 18-month-old Quarter Horses betweendays 0 and 60 of training. ${ }^{103}$ Automated horse walkers (AHW) are a common way to control exercise and Keller and Spengler stated that there will be positive bone change if the loading threshold on the AHW is around $25 \%$ of the maximum loading effort. ${ }^{104}$ However, Hoekstra et al. ${ }^{37}$ observed that boxed horses still lost bone mass when walked for an hour each day. ${ }^{37}$ Bolwell et al. ${ }^{102}$ reported an association between increased hand walking or time spent on an AHW for yearlings and the incidence of later training interruptions, of which 9 out of 17 were due to DMD. ${ }^{102}$ This study lacked statistical power and variables such as turn-out time, herd dynamic, and paddock size were not included. Additionally, speeds on AHW have been omitted in past studies making results difficult to interpret.

Training: In humans it has been shown that 10 minutes of bone loading per day causes a training response. ${ }^{105}$ The McIII of a young Thoroughbred adapts to training in different ways according to the type of training. How long it takes for bone to respond to various training regimes is not known. ${ }^{106}$ Thoroughbred training methods are individualist with 'Traditional' and 'Classical' regimes involving daily long slow work, (perhaps 1.5 to $2.5 \mathrm{~km}$ per day) at a "gallop" (United States) or "canter" (Europe), with a "breeze" (United States) or "racing gallop "(Europe) of perhaps $0.8 \mathrm{~km}$ every two or more weeks. ${ }^{85}$ Interval training is practised by some yards where the horse is either walked or trotted between bouts of exercise.

Strain rates need to be high (2,000 to 3,500 microstrains) to induce and maintain maximum peak strain levels over the McIII. ${ }^{45}$ In a New Zealand study, the left diaphyses of two-year-old Thoroughbreds from three different groups (pasture only, medium exercise, and intensive exercise) were analysed in vivo using double-calcein labelling and post-mortem CT scanning. ${ }^{107}$ Whilst Firth et al. ${ }^{107}$ were able to create benchmarks for future studies, the point at which changes to bone size and density occurred could not be isolated, though BMD did increase ahead of bone size. ${ }^{107}$ Primary haversian activity was highest in the intensively exercised horse, but no secondary haversian activity (SHA) was identified. Whether this was due to the early stages of subperiostial microdamage is unknown. Such SHA would be expected during remodelling and/or during active microdamaging. ${ }^{40}$

Boston and Nunamaker stated, in accordance with Wolff's Law, that training must mimic racing (regular high speeds), so that the bone adapts to racing. ${ }^{85}$ Trotting was found to have no effect on McIII adaptations in their study of 226 two-year-olds. Contrary to this, Cogger et al. ${ }^{12}$ stated that the incidence of DMD was higher in Thoroughbreds who covered more distance at speeds of $>890 \mathrm{~m} /$ min in the first ten weeks of training. ${ }^{12}$ Cogger et al. ${ }^{12}$ also stated that different distances galloped at speeds of $800-890 \mathrm{~m} / \mathrm{min}$ made no difference to the incidence of DMD. ${ }^{12}$ Clegg argued that risk of DMD is reduced when distances fast cantered begin to accumulate over time and that high speed exercise introduced quickly (in 1month) was detrimental. ${ }^{16}$ Jackson et al. ${ }^{108}$ stated that fast work should be avoided in the early stages of training. ${ }^{108}$ Cogger et al.${ }^{12}$ Clegg, ${ }^{16}$ and Jackson ${ }^{108}$ reported that short bursts of high intensity training, introduced slowly, leads to more controlled adaptive change and a reduction in the risk of microfracture. Hence, the regular use of high speed breezes reduces the incidence of DMD.

Furosemide: Furosemide, a loop diuretic, has been controversially used in horseracing in the United States for over 50years to reduce incidences of exercise-induced pulmonary haemorrhage. In humans, Furosemide has been linked to bone mass loss and osteoporotic fractures. ${ }^{109}$ It also raises urinary calcium loss that can lead to secondary hyperparathyroidism. ${ }^{110}$ In the United States, $98 \%$ of racehorses receive Furosemide. ${ }^{111}$ Data on how this drug acts on osteoblastic cells are limited and Kim et al. ${ }^{112}$ finding that it had no direct effect on osteocalcin levels or human bone marrow stromal osteoprogenitor cells, suggested that Furosemide may be affecting calcium metabolism indirectly. ${ }^{112}$ However, their data may have been flawed due to the use of second passage cells, limited osteoblast function data, and noninclusion of the effects of Furosemide on osteoclasts. More research into the effects of Furosemide on equine bone is needed. However, given that DMD often occurs in horses prior to their first racing start, it is unlikely to play a role in the development of this problem though it could possibly have an influence on bone health once racing, though it is likely the effects are minor compared to other factors.

\section{Precursor to catastrophic bone failure}

In a study of 1,178 flat racing Thoroughbreds from 13 yards in the United Kingdom, stress fractures were the most common (57\%), with the McIII being affected most often. Of the five fatal fractures, one was a mid-shaft McIII. Over three-quarters of fractures occurred in training, whilst $22.3 \%$ occurred in racing. ${ }^{90}$

Micro-fractures, left unchecked, can predispose bone fatigue and ultimate catastrophic fracture ${ }^{113}$ due to an accumulation of cyclic loading of the McIII, rather than just one single traumatic event. ${ }^{114}$ In a study of Californian racehorses, $89 \%$ of horses with catastrophic fractures were found to have underlying stress-related bone pathology. ${ }^{11}$ On racetracks in the United States, 10 to $12 \%$ of all fatal injuries have been compound fractures of the diaphyseal dorso-lateral cortex of the McIII in horses with a history of DMD. ${ }^{23}$

Incomplete, longitudinal, and proximo-palmar fractures of the McIII have also been reported as being caused by micro-fracture as a corollary of cyclic loading. ${ }^{114-117}$ Dallap et al. ${ }^{114}$ reported a predominance of dorso-lateral stress fractures in the left McIII's of male 3year-olds. ${ }^{114}$ Nunamaker reported that "saucer" fractures tend to only be found in horses that previously experienced DMD. ${ }^{3}$

\section{Biomarkers}

Several studies have been conducted to show how biomechanical markers of bone metabolism reflect skeletal response to exercise in horses. ${ }^{118-120}$ In a study by Inoue et al., biomarker response to exercise 
intensity was measured in 4year-old Thoroughbred stallions exercised on a treadmill for 3 weeks. ${ }^{121}$ Exercise was increased weekly and serum and urinary biomarkers were analysed at the end of each week. Low speed exercise had no influence on OC but it was suppressed at high speeds. As exercise increased, HYP and DPD diminished. The results suggest that high speed exercise leads to a reduction in bone resorption. However, the sample was small and 1week of exercise is short.

Nielsen et al. ${ }^{38}$ in a longer experiment (16weeks), found an initial rise and then decline in serum OC betweendays 14 and 42 in 2yearold Quarter Horses entering training. ${ }^{38}$ Interestingly, Price et al. ${ }^{118}$ found that indicators of bone formation (PICP and BAP) were raised in 2year-old Thoroughbreds immediately after commencing exercise regimes, suggesting an increase in bone turnover from the onset of training. ${ }^{118}$ Such varied results suggest that, as an indicator of bone metabolism, biomarker data should be used in conjunction with other analytical techniques such as $\mathrm{x}$-ray or scintigraphy for more meaningful results.

\section{Conclusion}

Data and study results in this review are varied and often contradictory, reflecting the difficulties involved in Thoroughbred exercise research. Costs, logistics, multiple variables, and a lack of specialised technology are problematic. Global variations in racehorse management, racing practices, and terminology add to the research variables and make comparisons difficult. Most available data are still predominantly from the United States, where DMD is common. Experiments examining load and strain in control versus treatment groups are problematic due to the inability to accurately record all movements that affect bone homeostasis. In vitro studies are cheaper and easier than in vivo but less informative due to an inability to fully replicate natural horse movements under laboratory conditions whilst longitudinal in vitro experiments often present with recording biases. There is a paucity of relevant training data which would increase understanding of the predisposition and earlier stages of DMD. Most research into musculo-skeletal problems of the racehorse use racing data, yet a horse spends more time training than racing and most injuries occur during training.

There are still conflicting views regarding the effects of racing horses before skeletal maturity and also when and how high speed exercise should be implemented to avoid skeletal damage. Research to date suggests that speed and distance should be increased gradually and should include some high speed work at full racing speed (according to Wolff's Law). Recent technological advances in GPS, gait analysis, nuclear medicine and equine genetics have led to improvements in data retrieval and should lead to an eventual increase in in vivo research and understanding of DMD. Biochemistry may help predict predisposition to DMD at an earlier stage so that prophylactic changes to training methods can be effected.

More research into human bone fatigue exists and is often heavily relied upon by the equine researcher. Horses experiencing DMD appear to be in pain so there is a welfare concern - a concern that esculates when the incidence of related catastrophic fractures of the McIII is taken into consideration. Changes to training regimes steeped in historical ritual will be hard to implement and is an ongoing challenge for the scientific researcher. Extensive 'box time' is a major feature of training and has an impact on BMD and strength. A need exists for more education amongst racing professionals to raise awareness regarding bone health - particularly when research has clearly shown bone loss associated with stalling of horses without access to high-speed exercise. There is reason to believe that the problem with DMD can be virtually eliminated if horses are afforded short bouts of high-speed exercise - either free-choice or forced - to maintain bone integrity and mitigate bone loss associated with stalling. Quite possibly it is the lack of high-speed exercise traditionally experienced during preparation for sales and during the early training under saddle that causes bone loss and the predisposition to DMD.

\section{Acknowledgements}

None.

\section{Conflict of interest}

Author declares that there is no conflict of interest.

\section{References}

1. Firth EC. The response of bone, articular cartilage and tendon to exercise in the horse. J Anat. 2006;208(4):513-526.

2. Firth EC, Rogers CW, van Weeren PR, et al. Mild exercise early in life produces changes in bone size and strength but not density in proximal phalangeal, third metacarpal and third carpal bones of foals. Vet $J$. 2011;190(3):383-389.

3. Nunamaker DM. On bucked shins. Proceedings of the $48^{\text {th }}$ Annual Convention of the American Association of Equine Practitioners. Orlando, FL, USA; 2002. p. 76-89.

4. Biewener AA. Allometry of quadrupedal locomotion: the scaling of duty factor, bone curvature and limb orientation to body size. $J$ Exp Biol. 1983;105:147-171.

5. Biewener AA. Musculoskeletal design in relation to body size. $J$ Biomech. 1991;24 Suppl 1:19-29.

6. Hildebrand M. The mechanics of horse legs. Amer Sci. 1987;75(6):594-601.

7. Les CM, Stover SM, Keyak JH, et al. The distribution of material properties in the equine third metacarpal bone serves to enhance sagittal bending. J Biomech. 1997;30(4):355-361.

8. Boyde A, Firth EC. Musculoskeletal responses of 2year-old Thoroughbred horses to early training. 8. Quantitative back-scattered electron scanning electron microscopy and confocal fluorescence microscopy of the epiphysis of the third metacarpal bone. New Zealand Vet J. 2005;53(2):123-132.

9. Rubio-Martinez LM, Cruz AM, Gordon K, et al. Mechanical properties of subchondral bone in the distal aspect of third metacarpal bones from Thoroughbred racehorses. Amer J Vet Res. 2008;69:1423-1433.

10. Gibson VA, Stover SM, Martin RB, et al. Fatigue behaviour of the equine third metacarpus: mechanical property analysis. $J$ Ortho Res. 1995;13(6):861-868.

11. Stover SM, Ardans AA, Read DH, et al. Patterns of stress fractures associated with complete bone fractures in racehorses. Proceedings of the 39th American Association of Equine Practitioners, San Antonio, TX, USA; 1993. p. 131-132.

12. Cogger N, Evans DL, Hodgson DR, et al. Incidence rate of musculoskeletal injuries and determinants of time to recovery in young Australian Thoroughbred racehorses. Aust Vet J. 2008;86(12):473-480.

13. Norwood G. The bucked shin complex in Thoroughbreds. Proceedings of the 24th Convention of the American Association of Equine Practice. St. Louis MO, USA; 1978. p. 319-335. 
14. Buckingham SHW, Jeffcott LB. Shin soreness: a survey of Thoroughbred trainers and racetrack veterinarians. Austr Equine Vet. 1990;8:148-153.

15. Bailey CJ, Reid SW, Hodgson DR, et al. Impact of injuries and disease on a cohort of two - and three-year-old thoroughbreds in training. Vet Rec. 1999;145(17):487-493.

16. Clegg PD. Musculoseletal disease and injury, now and in the future. Part 1: Fractures and fatalities. Equine Vet J. 2011;43(6):643-649.

17. Japanese Racing Association. Annual Report on Racehorse Hygiene. Number of new patients. 1999:24-44 p.

18. Katayama Y, Ishida N, Kaneko M, et al. The influence of exercise intensity on bucked shins complex. J Equine Sci. 2001;12:139-143.

19. Perkins NR, Rogers CW, Firth EC, et al. Musculoskeletal responses of 2 -year-old Thoroughbred horses to early training. 3. In vivo ultrasonographic assessment of the cross-sectional area and echogenicity of the superficial digital flexor tendon. New Zealand Vet J. 2004;52(5):280-284.

20. Verheyen KLP, Henley WE, Price JS, et al. Training-related factors associated with dorsometacarpal disease in young Thoroughbred racehorses in the UK. Equine Vet J. 2005;37(5):442-448.

21. Setterbo JJ, Garcia T, Campbell I, et al. Forelimb kinematics of galloping thoroughbred racehorses measured on dirt, synthetic and turf track surfaces. In: Estivalet M, Brisson P, editors. The Engineering of Sport 7. Paris: Springer; 2008. p. 437-446.

22. Finsen V, Andra S. Accuracy of visually estimated bone mineralisation in routine radiographs of the lower extremity. Skel Rad. 1988;17(4):270-275.

23. Nunamaker DM, Butterweck DM, Provost MT. Fatique fractures in Thoroughbred racehorses: relationship with age, peak bone strain and training. J Orthop Res. 1990;8(4):604-611.

24. Nunamaker DM, Butterweck DM, Black J. In vitro comparison of Thoroughbred and Standardbred racehorses with regard to local fatigue failure of the third metacarpal bone. Amer J Vet Res. 1991;52:97-100.

25. Ross MW. The Metatarsal Region. In: Ross MW, Dyson S, editors. Lameness in the Horse. Missouri, USA: Elsevier-Saunders; 2011. p. 499-508.

26. Gaschen L, Burba DJ. Musculoskeletal Injury in Thoroughbred Racehorses. Vet Clin North Amer: Equine Pract. 2012;28(3):539-536.

27. Firth EC. Problems in quantifying bone response to exercise in horses: a review. New Zealand Vet J. 2004;52(5):216-229.

28. Hiney KM, Nielsen BD, Rosenstein D. Short-duration exercise and confinement alters bone mineral content and shape in weanling horses. $J$ Anim Sci. 2004;82(8):2313-2320.

29. Pearson OM, Lieberman DE. The aging of 'Wolff's law: Ontogeny and responses to mechanical loading in cortical bone. Yearbook Phys Anthro. 2004;47:63-99.

30. Frost HM. Bone remodelling and its relationship to metabolic bone diseases. Springfield: Thomas; 1973.

31. Frost HM. Bone modelling and skeletal modelling errors. Wiley library. 1973;61(1):84.

32. Currey JD. The many adaptations of bone. $J$ Biomech. 2003;36(10):1487-1495.

33. Taylor D, Casolari E, Bignardi C. Predicting stress fractures using a probabilistic model of damage, repair and adaptation. J Orthop Res. 2004;22(3):487-494.

34. Warden SJ, Hurst JA, Sanders MS, et al. Bone adaptation to a mechanical loading programme significantly increases skeletal fatigue resistance. J Bone Miner Res. 2005;20(5):809-816.
35. Whitton RC, Trope GD, Ghasem-Zadeh A, et al. Third metacarpal condylar fatigue fractures in equine athletes occur within previously modelled subchondral bone. Bone. 2010;47(4):826-831.

36. Stover SM. The epidemiology of Thoroughbred racehorse injuries. ClinTech Equine Pract. 2003;2(4):312-322.

37. Hoekstra K, Nielsen B, Orth M, et al. Comparison of bone mineral content and biochemical markers of bone metabolism install-vs. Pasture-reared horses. Equine Vet J. 1999;Supp 1 30:601-604.

38. Nielsen BD, Potter GD, Greene LW, et al. Characterization of changes related to mineral balance and bone metabolism in the young racing Quarter Horse. Journal of Equine Veterinary Science. 1998;18(3):190-200.

39. Scotti E, Jeffcott LB. The hock as a potential site for non-invasive bone measurement. Equine Vet J. 1988;Suppl 6:93-98.

40. Burr DR, Robling AG, Turner CH. Effects of biomechanical stress on bones in animals. Bone. 2002;30(5):781-786.

41. Lieberman DE, Polk JD, Demes B. Predicting long bone loading from cross-sectional geometry. Amer J Phys Anthropol. 2004;123(2):156-171.

42. Rubin CT, Lanyon LE. Limb mechanics as a function of speed and gait: a study of functional strains in the radius and tibia of horse and dog. $J$ Exp Biol. 1982;101:187-211.

43. Davies HM. The effects of different exercise conditions on metacarpal bone strains in Thoroughbred Racehorses. Pferdeheilkunde. 1996;12(4):666-670.

44. Rubin C, Turner AS, Mallinckrodt C, et al. Mechanical strain, induced noninvasively in the high-frequency domain, is anabolic to cancellous bone, but not cortical bone. Bone. 2002;30(3):445-452.

45. Davies HM, Merritt JS. Surface strains around the midshaft of the third metacarpal bone during turning. Equine Vet J. 2004;36(8):689-692.

46. Davies HM. Estimating peak strains associated with fast exercise in thoroughbred racehorses. Equine Vet J. 2006;Suppl 36:383-386.

47. Gross TS, McLeod KJ, Rubin CT. The skeletal consequences of extreme physiological activity: The comparative strain milieu generated by treadmill and field conditions. Transactions of the $36^{\text {th }}$ Annual Meeting of the Orthopaedic Research Society, Adept Printing. 1990. 108p.

48. Moreira RC, Pereira CAM, Jose P, et al. Evaluation of bone biomechanical properties in different regions of the equine third metacarpus. $J$ Musculoskel Res. 2012;15(3):1-11.

49. Ruff CB, Hayes WC. Cross-sectional geometry of Pecos Pueblo femora and tibiae-a biomechanical investigation 1. Method and general patterns of variation. Amer J Phys Anthropol. 1983;60(3):359-381.

50. Gross TS, McLeod KJ, Rubin CT. Characterizing bone strain distributions in vivo use three triple rosette strain gages. J Biomech. 1992;25(9):1081-1087.

51. Firth EC, Rogers CW, van Weeren PR, et al. The effect of previous conditioning exercise on diaphyseal and metaphyseal bone to imposition and withdrawal of training in young Thoroughbred horses. Vet J. 2012;192(1):34-40.

52. Davies HM. The timing and distribution of strains around the surface of the midshaft of the third metacarpal bone during treadmill exercise in one thoroughbred racehorse. Austr Vet J. 2005;83(3):157-162.

53. Davies HM, Mc Carthy RN. Strain in the yearling metacarpus during locomotion. Equine Vet J. 1994;Suppl 17:25-28.

54. Rubin CT, Seeherman H, Qin YX, et al. The mechanical consequences of load bearing in the equine third metacarpal across speed and gait: The non uniform distributions of normal strain, shear strain, and strain energy density. J Fed Amer Soc Exp Biol. 2013;27(5):1887-1894. 
55. Goodman NL. Quarter Horse racetrack practice. Proceedings of the 33rd American Association of Equine Practioners. New Orleans, Louisiana, USA; 1987. p. 835-841.

56. Nunamaker DM. The Bucked-Shin Complex. In: Ross, Dyson S, editors. Lameness in the Horse. Missouri: Elsevier-Saunders; 2011. p. 953-960.

57. Nunamaker DM, Butterweck DM, Provost MT. Some geometric properties of the third metacarpal bone: a comparison between the Thoroughbred and Standardbred racehorse. J Biomech. 1989;22(2):129-133.

58. Bertone AL. The metacarpus and metatarsus. In: Baxter GM, editor. Adams and Stashak's Lameness in Horses. Chichester, UK: Wiley-Blackwell; 2011. p. 621-645.

59. Pagan JD, Nash D. Nutrition of the young equine athlete. In: Pagan JD, editor. Advances in Equine Nutrition IV. Nottingham: Nottingham University Press; 2009. p. 161-171.

60. Bertram JEA, Swartz SM. The law of bone transformation: a case of crying Wolff? Biol Rev. 1991;66(3):245-273.

61. Holt BM, Ruff CB, Trinkaus E. The Wolff's law debate: throwing out the water, but keeping the baby. Amer J Phys Anthro. 2004;S38:115-116.

62. Buckingham SHW, McCarthy RN, Anderson GA, et al. Ultrasound speed in the metacarpal cortex-a survey of 347 Thoroughbreds in training. Equine Vet J. 1992;24(3):191-195.

63. Riggs CM, Evans GP. The microstuctural basis of the mechanical properties of equine bone. Equine Vet Ed. 1990;2(4):197-205.

64. Stover SM, Pool RR, Martin RB, et al. Histological features of the dorsal cortex of the third metacarpal bone mid diaphysis during postnatal growth in Thoroughbred horses. J Anat. 1992;181(Pt 3):455-469.

65. Back W, Shamhardt HC, Hartman W, et al. Predictive value of foal kinematics for the locomotor performance of adult horses. Res Vet Sci. 1995;59(1):64-69.

66. Back W, Schamhardt HC, Savelberg HH, et al. How the horse moves: 1 . Significance of graphical representations of equine forelimb kinematics. Equine Vet J. 1995;27(1):31-38.

67. Butcher MT, Ashley-Ross MA. Fetlock joint kinematics differ with age in Thoroughbred racehorses. J Biomech. 2002;35(1):563-571.

68. Lemazurier E, Toquet MP, Fortier G, et al. Sex steroids in serum of prepubertal male and female horses and correlation with bone characteristics. Steroids. 2002;67:361-369.

69. Wink CS, Felts WJL. Effects of castration on the bone structure of male rats: A model of osteoporosis. Calcif Tissue Intern. 1980;32(1):77-82.

70. Davies HMS, McCarthy RN, Jeffcott LB. Surface strain on the dorsal metacarpus of thoroughbreds at different speeds and gaits. Cells Tiss Org. 1993;146(2-3):148-153.

71. Demissie S, Dupuis J, Cupples LA, et al. Proximal hip geometry is linked to several chromosomal regions: genome-wide linkage results from the Framingham Osteoporosis Study. Bone. 2007;40(3):743-750.

72. Havill M, Mahaney MC, Binkley TL, et al. Effects of genes, sex, age and activity on BMC, bone size and areal and volumetric BMD. J Bone Min Res. 2007;22(5):737-746.

73. Farber CR, Kelly SA, Baruch E, et al. Identification of quantitative trait loci influencing skeletal architecture in mice: emergence of Cdh11 as a primary candidate gene regulating femoral morphology. J Bone Min Res. 2011;26(9):2174-2183.

74. Wallace IJ, Tommasini SM, Judex S, et al. Genetic variations and physical activity as determinants of limb bone morphology: An experimental approach using a mouse model. Am J Phys Anthropol. 2012;148(1):24-35.
75. Runyan SM, Stadler DD, Bainbridge CN, et al. Familial resemblance of bone mineralization, calcium intake, and physical activity in early-adolescent daughters, their mothers, and maternal grandmothers. The Journal of the Academy of Nutrition and Dietetics. 2003;103(10):1320-1325.

76. Seeman E, Hopper JL, Young NR, et al. Do genetic factors explain associations between muscle strength, lean mass, and bone density? A twin study. Am J Physiol. 1996;270(2 Pt 1):E320-E327.

77. Davies HM. Relationships between third metacarpal bone parameters and surface strains. Equine Vet J. 2001;Suppl 33:16-20.

78. Wilson AM, McGuigan MP, Su A, et al. Horses damp the spring in their step. Nature. 2001;414(6866):895-899.

79. Crevier-Denoix N, Falala S, Holden-Douilly L, et al. Comparative kinematic analysis of the leading and trailing forelimbs of horses cantering on a turf and synthetic surface. Equine Vet J. 2013;Suppl 45:54-61.

80. Setterbo JJ, Garcia TC, Campbell IP, et al. Hoof accelerations and ground reaction forces of Thoroughbred racehorses measured on dirt, synthetic, and turf track surfaces. Am J Vet Res. 2009;70(10):1220-1229.

81. Setterbo JJ, Yamaguchi A, Hubbard M, et al. Effects of equine racetrack surface type, depth, boundary area, and harrowing on dynamic surface properties measured using a track-testing device in a laboratory setting. Sports Engineering. 2011;14(2-4):119-137.

82. Peterson ML, Reiser RF, Kuo PH, et al. Effect of temperature on race times on a synthetic surface. Equine Vet J. 2010;42(4):351-357.

83. Moyer W, Spencer PA, Kallish M. Relative incidence of dorsal metacarpal disease in young Thoroughbred racehorses training on two different surfaces. Equine Vet J. 1991;23(3):166-168.

84. Bolwell CF, Rogers CW, French NP, et al. Exercise in Thoroughbred yearlings during sales preparation: A cohort study. Equine Vet $J$ 2012;44(1):20-24.

85. Boston RC, Nunamaker DM. Gait and speed as exercise components of risk factors associated with onset of fatigue injury of the third metacarpal bone in 2-year-old Thoroughbred racehorses. Am J Vet Res. 2000;61(6):602-608.

86. Leach DH, Sprigings E. Gait fatigue in the racing thoroughbred. Journal of equine medicine and surgery. 1979;3:436-443.

87. Louis O, Van Den WinkelP, Covens P, et al. Size of cortical bone and relationship to bone mineral density assessed by quantitative computed tomography image segmentation. Invest Radiol. 1993;28(9):802-805.

88. Reilly GC, Currey JD, Goodship AE. Exercise of young thoroughbred horses increases impact strength of the third metacarpal bone. J Orthop Res. 1997;15(6):862-868.

89. Bathe AP. 245 Fractures in Thoroughbred racehorses: Results of a 2 year prospective study in Newmarket. American Association of Equine Practitioners, 40th Annual convention. Vancouver, BC, Canada; 1994. p. 175-176.

90. Verheyen KLP, Wood JLN. Descriptive epidemiology of fractures occurring in British Thoroughbred racehorses in training. Equine Vet J. 2004;36(2):167-173.

91. Boden LA, Anderson GA, Charles JA, et al. Risk of fatality and causes of death of Thoroughbred horses associated with racing in Victoria, Australia: 1989-2004. Equine Vet J. 2006;38(4):312-318.

92. Clanton C, Kobluk C, Robinson RA, et al. Monitoring surface conditions of a Thoroughbred racetrack. J Am Vet Med Assoc. 1991;198(4):613-620.

93. Fredricson I, Drevemo S. A New Method of Investigating Equine Locomotion. Equine Vet J. 1971;3(4):137-140. 
94. Hobbs SJ, Licka T, Polman R. The difference in kinematics of horses walking, trotting and cantering on a flat and banked $10 \mathrm{~m}$ circle. Equine Vet J. 2011;43(6):686-694.

95. Hobbs SJ, Richards J, Matuszewski B, et al. Development and evaluation of a noninvasive marker cluster technique to assess three-dimensional kinematics of the distal portion of the forelimb in horses. Am J Vet Res. 2006;67(9):1511-1518.

96. Bell RA, Nielsen BD, Waite K, et al. Daily access to pasture turnout prevents loss of mineral in the third metacarpus of Arabian weanlings. $J$ Anim Sci. 2001;79(5):1142-1150.

97. Nugent GE, Law AW, Wong EG, et al. Site and exercise related variation in structure and function of cartilage from equine distal metacarpal condyle. Osteoarthritis Cartilage. 2004;12(10):826-833.

98. Kawcak CE, McIlwraith CW, Firth EC. Effects of early exercise on metacarpophalangeal joints in horses. Am J Vet Res. 2010;71(4):405-411.

99. Matkovic V, Jelic T, Wardlaw GM, et al. Timing of peak bone mass in Caucasian females and its implication for the prevention of osteoporosis. Inference from a cross-sectional model. $J$ Clin Invest. 1994;93(2):799-808

100. Cornelissen BPM, van Weeren PR, Ederveen AG, et al. Influence of exercise on bone mineral density of immature cortical and trabecular bone of the equine metacarpus and proximal sesamoid bone. Equine Vet J. 1999;Suppl 31:79-85.

101. Buckingham SHW, Jeffcott LB. Skeletal effects of a long term submaximal exercise programme on Standardbred yearlings. In: Gillespie JR, Robinson NE, editors. Equine Exercise Physiology 3. California, USA: ICEEP Publications; 1991. p. 411-418.

102. Bolwell CF, Rogers CW, French NP, et al. Association between yearling exercise and interruptions during race training in Thoroughbred racehorses. Am J Vet Res. 2012;73(10):1610-1616.

103. BD Nielsen, GD Potter, EL Morris, et al. Changes in the third metacarpal bone and frequency of bone injuries in young Quarter Horses during race training observations and theoretical considerations. Journal of Equine Veterinary Science. 1997;17(10):541-549.

104. Keller TS, Spengler DM. Regulation of bone stress and strain in the immature and mature rat femur. J Biomech. 1989;22(11-12):1115-1127.

105. Goodship AE, Cunningham JL, Oganov V, et al. Bone loss during long term space flight is prevented by the application of a short term impulsive mechanical stimulus. Acta Astronaut. 1998;43(3-6):65-75.

106. Riggs CM. Fractures -a preventable hazard of racing Thoroughbreds? Vet J. 2002;163(1):19-29.

107. Firth EC, Rogers CW, Doube M, et al. Musculo-skeletal responses of 2year-old Thoroughbred horses to early training. 6. Bone parameters in the third metacarpal and metatarsal bones. $N \mathrm{Z} \mathrm{Vet} J$ 2005;53(2):101-112.
108. Jackson BF, Lonnell C, Verheyen KL, et al. Biochemical markers of bone metabolism and risk of dorsal metacarpal disease in two year old Thoroughbreds. Equine Vet J. 2005;37(1):87-91.

109. Arampatzis S, Gaetcke LM, Funk GC, et al. Diuretic-induced hyponatremia and osteoporotic fractures in patients admitted to the emergency department. Maturitas. 2013;75(1):81-86.

110. Fujita T, Chan JC, Bartter FC. Effects of oral furosemide and salt loading on parathyroid function in normal subjects. Physiological basis for renal hypercalciuria. Nephron. 1984;38(2):109-114.

111. Larkin M. Uniform horse-racing rules gaining momentum: $10 \mathrm{ju}-$ risdictions have signed on to national reforms. J Am Vet Med Assoc. 2014;244(4):386-390

112. Kim $\mathrm{CH}$, Kim SW, Kim GS. Effects of hydrochlorothiazine and furosemide diuretics on human bone marrow stromal osteoprogenitor cells. Metabolism. 2000;49(1):17-21.

113. EJ Davidson, MW Ross. Clinical Recognition of Stress-Related Bone Injury in Racehorses. Clin Techniques in Equine Practice. 2003;2(4):296-311.

114. Dallap BL, Bramlage LR, Embertson RM. Results of screw fixation combined with cortical drilling for treatment of dorsal cortical stress fractures of the third metacarpal bone in 56 Thoroughbred racehorses. Equine Vet J. 1999;31(3):252-257.

115. Riggs CM. Incomplete fracture of the proximopalmar aspect of the third metacarpal bone. Equine Veterinary Education. 1994;6(5):263-267.

116. GL Pinchbeck, NG Kriz. Two cases of complete longitudinal fracture of the third metacarpal bone. Equine Veterinary Education. 2001;13(4):187-193.

117. Powell SE, Ramzan PH, Haed MJ, et al. Standing magnetic resonance imaging detection of bone marrow oedema-type signal pattern associated with subcarpal pain in 8 racehorses: A prospective study. Equine Vet J. 2010;42(1):10-17.

118. Price JS, Jackson B, Eastell R, et al. The response of the skeleton to phys ical training: a biochemical study of horses. Bone. 1995;17(3):221-227.

119. Vervuert I, Coenen M, WedemeyerU, et al. Calcium homeostasis and intact plasma parathyroid hormone during exercise and training in young Standardbred horses. Equine Vet J. 2002;34(7):713-718.

120. Nielsen BD, Spooner HS. Small changes in exercise, not nutrition, often result in measurable changes in bone. Comp Exer Phys. 2008;5:15-20.

121. Inoue Y, Matsui A, Asai Y, et al. Response of biochemical markers of bone metabolism to exercise intensity in Thoroughbred Horses. $J$ Equine Sci. 2008;19(4):83-89. 